\title{
Standards of Teaching Reading in the Secondary Schools in Egypt in the Light of Some International Experiences: Historical Study
}

\author{
Dr. Eman Ahmed Mohamed Hussein Elian \\ Researcher at the National Center for Educational Research and Development (NCERD) \\ Curricula Development Research Department \\ Email: emanelian@gmail.com
}

Doi:10.5901/ajis.2016.v5n3s1p504

\begin{abstract}
This research aimed at knowing the standards of teaching reading that have been developed in Egypt at the secondary level through the period (2003- 2015). And to what extent they are in line with the international standards applied in some international systems and achieved high scores in reading level of their students. There is a complaint from the weakness of the secondary schools' students in reading, and this is, of course, due to standards of teaching reading, for not applying these standards when teaching reading in secondary schools. Consequently, this becomes the main obstacle to success in university; for not having the right understanding of what they read in the non-linguistic courses. To achieve the objectives of the research, the historical method was used; where access to primary and secondary sources about standards of teaching reading in the secondary schools in Egypt in the period (2003-2015), then analysis and interpretation had been done to reach the most important developments during this time period. Then a description of some international experiences, namely: some states in USA (New Jersey- North Carolina- Pennsylvania), standards of International "Ila", New Zealand, Qatar, and the United Arab Emirates, had been done in order to determine their applicability in the Egyptian educational system. Finally, the research submitted a proposal for the standards of teaching reading in Egypt in the light of the results of historical study and the analyses of the international experiences, putting in consideration the Arabian culture, the requirements of the Egyptian society, and the characteristics and needs of secondary schools' students in Egypt.
\end{abstract}

Keywords: Standards, Teaching Reading, Secondary Schools, Egypt

\section{Introduction}

Reading plays a key role in the progress of the societies and promoting it and growing the minds of its individuals, as it is a way of obtaining information and knowledge, satisfying tendencies, gaining experiences, progressing in the various subjects. The Government education plan in England recognized the vital importance of reading, and gave priority to continually raising the reading standards at schools, and since 2010, the concentration was on improving reading in general, setting new national curriculums to encourage reading, as the students who can read overwhelmingly more likely to succeed at school and achieve good qualifications (Department of Education, 2015, 8).

The developed countries, led by the United States of America and European countries embarked adopting education on the basis of the standards, followed by number of Arab countries, such as Qatar and UAE, and this type of development means that the curriculum submitted to the student are subject to the indicators and international standards, as the Arabian student can't achieve real achievements, unless he masters the necessary skills and knowledge, which prepares him to join local and international universities (Al-Nuseirat, 2015, 1).

\subsection{Sensing the Problem}

Mastering the Arabic language represents a strategic goal of the public education for any Arab country, and this mastering is achieved when fulfilling the Arabic language standards in the public Education, as the standards determines precisely the acquired by the learners of Arabic languages' skills, literatures, concepts, knowledge and tendencies towards it, its teaching and learning. The periodic review of the standard levels of the Arabic language content and standards of the rest of the elements of the Arabic language system are the basis of developing these standards (Fadlallah, 2016, 88), but the results and recommendations of some following researches and studies proved the following: not engaging or activating of the teaching of reading standards when teaching and educating it at schools, which requires the development of the standards that can be implemented on the ground, and the Standards of Teaching 
Reading are known in the countries achieved successes in the reading levels of its students and following the international models (Al-Najjar, 2010, 167), not achieving the international standards of Teaching Reading for the majority of the students (Al-Laboudi, 2011, 244), and the necessity of paying attention to the study, determining and trying the Standards of Teaching Reading to realize the extent of its validity for what it seeks, as it is one of the most important approachs of education development (Al-Kandari, et al., 2010., 248), and as there are no studies about the reading standards in the secondary school books, and no comparisons control and fulfill the standards were studied to find enough evidences for the curriculums used with hundreds of thousands of students, who suffer from reading, and recommended further research on reading, because there is an urgent need to develop the programs for secondary school students to improve reading outcomes for the students suffered from difficulties in reading in their important secondary school years (Slavin, Cheung, Groff and Lake, 2008, 308-309), and the importance of employing the international standards for Teaching Reading when developing reading position (Kalsh, 2016, 292).

\subsection{Research Problem}

The current research problem determines the need of knowing the Standards of Teaching Reading, which was set in Egypt through various periods of time, and its undergone development, renewal and renovation, the extent of its compliance with the international standards of Teaching Reading in some international experiences, in which these standards were applied in its educational system, as this affects the students level in reading and their following up to the international standard level, which enable their peers at the same age in these countries to pass the tests successfully.

\subsection{Research Questions}

The current research attempts to answer the following questions:

1. What is the development and innovation took place in Teaching Reading in some international experience?

2. What are the Standards of Teaching Reading in the secondary schools in some international experiences?

3. What is the difference between the standards of Teaching Reading at the secondary schools in Egypt and some international experiences?

4. What are the reading standards at the secondary schools in Egypt in the light of some international experience?

\subsection{Research Goals}

The current research aims the following:

1. Determining the development, renewal and renovation that occurred in the Teaching Reading at the second schools in Egypt through the various periods of time.

2. Teaching Reading is realized in the secondary schools in some international experience.

3. Setting the difference between Standards of Teaching Reading at the secondary schools in Egypt and some international experiences.

4. Reaching Standards of Teaching Reading at the secondary schools in Egypt in the light of some international experiences.

\subsection{Research Importance}

The importance of the current research is represented in the following:

1. Providing time and qualitative sequential development, renewal, innovation Standards of Teaching Reading at the secondary schools in Egypt through various periods of time>

2. Providing the field with international standards for Teaching Reading at the secondary schools in some international experiences, which achieved success in this field.

3. Determining the reading standards at the secondary schools in Egypt in the light of the international standards to Teaching Reading at some international experiences.

4. Opening the way for future experiences concerning the international standards to teach languages arts in various educational stages. 


\subsection{Research Terminology}

1. Standards: It is the characteristics and product's features, which the student represents in the educational field, and represents he performance standard, which expectation degree obtained by the student refers to it in a meaningful way (Ministry of Education, Ontario, 2010, 22), it describes what the students should know and be able to do when leaving the public education system (South Carolina Department of Education, 2015, 13).

2. Reading is defined as, "a complicated and complex mental process, includes definition, pronunciation, interpretation of symbols received by the reader by his eyes, with the meanings understanding, which are expressed by those symbols, in additions to the innovative thinking and its criticism" (Yunis, 2016, 5).

3. Secondary school is procedurally defined in this research as, " the public school, which receives primary and preparatory school education outputs, and brings out the higher education inputs, which is a stage in which the students starts choose his major fields; whether its science or literature.

\subsection{Research Limits}

The current research is limited to the following:

1. The secondary school, as it is the end of the Pre-university education, it is the final product of the public education stages in Egypt, after that the student enters the higher education, so the student moves with any deficiency or weakness in the higher education, as there is a direct relation between them.

2. Standards of Teaching Reading at the Secondary Schools at: (Egypt in 2003, 2005, 2015), (Qatar 2005), (UAE after the document of the year 2002), (ILA International standards 2010), (Some USA states; Northern Carolina 2010, Pennsylvania 2014, New Jersey, 2016) and (New Zealand).

\section{Research Methodology and Tools}

The current research uses the historical method, as it describes the past facts, and doesn't stop at mere description, but studies these facts and analyzes it on the basis of the precise scientific methodology, with an intention to reach to facts and generalizations" (Arab Organization for the education, Culture and Science, 2013, 128) and it is represented by the following tools:

1. Primary sources, represented in the method's documentation, including the Standards of Teaching Reading in the secondary schools in Egypt during the aforementioned historical times within the limits of the aforementioned research.

2. Secondary sources, represented in the descriptions or interpretations of standards, were set later - after the preparation of method's documents - by researchers, institutions or bodies; in order to be evaluated, analyzed and interpreted.

\subsection{Research Procedures}

The current research is taking the following steps:

1. Theoretical Framework, including: a brief about reading, its negligence impacts, standards and its importance.

2. Historical study procedures, including: analyzing and interpreting the Standards of Teaching Reading at the secondary schools in Egypt to determine the developments took place during the historical period specified in the research.

3. Reviewing the Standards of Teaching Reading at the secondary schools at some international experiences previously mentioned - analyzing and interpreting it, to realize the differences between them and the Standards of Teaching Reading in Egypt.

4. Submitting a suggested model of the Standards of Teaching Reading in Egypt, in the light of the historical study results and international experiences in conformity with the Egyptian educational system, Egyptian society requirements, Arab culture, and characteristics and needs of the students in this secondary schools .

\section{Theoretical Framework}

Reading is one of the means of fruitful knowledge contributes to solve the problems, and successfully pass the vital 
situations, rapprochement and understanding between individuals, as it is the key of everything in life (Soman, 2009,7374), therefore the community that reads is a civilized community characterized by intellectual and cultural unity of its individuals, so neglecting reading and not learning it leads to negative results at the individuals and communities level, while its development enables its individuals to adapt to life and serve their communities (Lafi, 2015, 137). Reading obtained this importance, as it is considered the main way for international understanding and innovation; it is the gate to education for its relation to innovation, invention, thinking, working and originality (Yunis, 2014, 212, 232).

The failure of many students and their negligence is more (non-linguistic) courses is not due to its difficulty, neither to their mental difficulties, but to their failure to acquire the mechanism of that knowledge, as they lack the right reading, and they don't have the precise understanding of what is read (Al-Harbi et al., N.D, 5), but it is considered the main obstacle to the success of the higher education for the lack of reading skills, as the students who suffer from that lacks the main requirements of academic study, which leads to more extensive reading, and thereby gain advanced vocabulary and understanding of the content ideologies (Slavin et al., 2008, 290).

Therefore, the United States of America set the common basic standards, the standards of the language arts standards, and concluded that it needs encouragement of all concerned parties to reconsider the Teaching Reading to achieve an effective education, and reading learning evaluation should be requested regardless of the form, as it is ultimately incomplete, if it is not effective (Applegate, Turner, and Applegate, 2010, 608), as basic standards of the countries were set to create the next generation from kindergarten to secondary school to ensure that all the students in undergraduate and professional stage are ready to achieve success in the standards of teaching reading no later than the Secondary Schools (Common Core State Standards Initiative, 2010, 3).

As the standards describe what the students should know, and be able to do when they leave the public education system (South Carolina Department of Education, 2015, 13), and focus on the most important, the standards of reading put the focus equally on the evolution of what the students read and the skill that they read with (Minnesota Department of Education, 2010, 77), as the need to the standards emerge as a result of the enormous increase in the available knowledge amount, which makes the precise choice inevitable, the rapid social changes necessitate the review of the curriculum in the light of the young people need and goals, and the rapid changes took place in the Egyptian and international society (Yunis, 2014, 480).

\section{Historical Study}

The primary and secondary sources of the Standards of Teaching Reading at the secondary schools were reviewed in Egypt in the years 2003, 2005 and 2015, after studying and analyzing it, the researcher found the following interpretations and conclusions:

- The coincidence between the three curriculum documents on setting the standards and determining the indicators of each standard, in order to determine the required learning outcomes.

- The standards indicators of the year 2003 for the Secondary Schools were set as whole under each standard without specifying the grade levels, while between 2005 and 2015, the indicators of each standard was placed for each school grade separately, and this explains the student growth level to the standard indicators and the extent of progression in complexity.

- The display of the standards of the year 2015 differed from the standards of the year 2003 and 2005, as the standards and its indicators were set through a vertical and horizontal organization shows the elevation of the indicators and its development in a revealing way in consistence with the students' abilities growth through the grades of the Secondary Schools, this is considered a renewal of standards display in terms of shape, while in qualitative terms, this helps in realizing the extend, succession, integration of indicators, themes and concepts without repetition.

- The language teaching approachs were employed in the three documents standards indicators in varying proportions.

- The standards of 2003 and 2005 participated in determining two standards only, they are: The goof understanding of the text, the fast reading while maintaining the understanding, this refers to a focus on reading comprehension, but the two standards indicators varied in each of the documents of them, this may be due to the emergence of some of the intellectual and social changes and their impact on students' needs and the community's requirements.

- The standards of 2015 added to the standards of 2005 and 2003 two standards, it is as follows: learning and pronouncing the language written symbols, appreciating the reading and criticize it, and this may be due to the 
interest in reading through multimedia, and the indirect impact of language (gestures and signals) to the understanding of the receiver and employing the complementary approach.

- The standards indicators of 2015 included instructing the student to the use of the modern technological techniques, and this is consistent with the digital age requirements in which the students live in.

- The standards' indicators of 2015 introduced by phonetics through the phonetic keys utilization "the stress, pause and intonation" when reading as per the situation and the context meaning in exchange of stress only in the standards indicators of 2005 , this refers to the usage of the interdisciplinary and communicative approach.

- The high level of complexity in the reading understanding standard in the standards of 2015 in the second and third secondary school grades, this may be due to the increase in knowledge and growing of the thinking of the students, as a result of the successive digital technology struggle.

\section{Standards of Teaching Reading at Some International Experiences}

Teaching Reading was reviewed at some international experiences - which are previously mentioned in the research limits - to determine the differences between them and the Standards of teaching reading in Egypt, the difference and agreement aspect are realized between these experiences, and then the new in this field shall be reached, and after studying and analyzing these standards, interpretation and conclusions are reached.

- Reading standards through two cores, it's as follows: Information and literary texts, identifying the standards of each aspect, but the indicators of each standard differs as per the privacy of each core, and this is in UAE, New Jersey, North Carolina, Pennsylvania in USA and ILA International, ILA International, New Jersey and North Carolina added a third core of the language includes also the standards, but Pennsylvania used one standard of the language core and set it among the two cores standards of Information and literary texts.

- The two cores standards of the Information and literary texts were defined in the United Arab Emirates on three standards: Analysis of words, fluency and vocabulary development, understanding absorption, literature response, and literary texts analysis. While the standards of these two cores were set in each of ILA International, New Jersey and North Carolina in four standards, as follows: main ideas and details, the art and text structure, knowledge and thoughts integration, reading and the complexity level of text. New Jersey added a fifth standard to the previous fourth standards, which are the vocabulary, acquisition and usage, which was a standard among the language core standards in each of ILA International and New Jersey.

- ILA International, New Jersey and North Carolina set three standards to achieve the language core stated in the reading standard, which are: Standard English language agreements, linguistics, vocabulary, acquisition and usage.

- The reading standards and its indicators in North Carolina are consistent with ILA International Standards completely, while New Jersey made some minor changes from replacement of some indicators or omission of standards and maintaining of indicators without mentioning the standards, this may be due to the standards of North Carolina and Ella were in one year 2010, but New Jersey standards were in the year 2016, this complies with the social and intellectual changes, but the difference is clear in Pennsylvania standards issued in 2014 than ILA standards, and can be due to the social requirements and students needs or adopting goals and philosophy of this particular state.

- ILA standards were set for reading to qualify the students to join the university or the career readiness, as well as in the USA states specified in the research, this is unlike Qatar and UAE standards, which were qualifying the college students.

- The UAE standards relied on the interdisciplinary and communicative approach, and the integration appeared between reading, and the Arabic language branches and skills, especially in the literary texts core, but for the informatics texts core, it included understanding, absorption, thoughts, arguments, views and thinking skills, and so on.

- Qatar document was different than other international experiences in the research, as it includes two levels of standards of each school grade of the Secondary Schools, an establishing level includes reviewing and enhancing the standards of the previous grades with adding some new standards to it, and advanced level including all the establishing level standard with addition of depth and diversity in handling topics, and the student chooses one of the two tracks, which ever more appropriate from him, it allow the existence of two levels for fast promotion of the superior students, and training the students as per their individual needs and personal ambitions. 
- Qatar standards were defined in for standards and indicators, which are as follows: Research and study skills, reading to know the meaning, understand the creation of the art of the writer, studying the literary texts; it relied on an interdisciplinary approach in the language.

- New Zealand's previous international experiences differed as it is as an educational system, it is divided into levels, each level includes a number of school grades, and the Secondary Schools is in the eighth level and a part of the seventh level, it includes the grades from the tenth to the thirteenth grade, the reading standards are set in it on the basis of reading processes and strategies, and its number is five, including several indicators, and the standards are: merging the information, processes and strategies sources, objectives and masses, thoughts and language features and structure.

- The clear difference in Standards of Teaching Reading in Egypt in most of the previous international experiences are set in the handling of these experiences to the standards through the following cores: Literary and informatics texts, and language, not setting the standards and indicators directly as in Egypt, Qatar and New Zealand, and it was set in order to qualify the college student and not for the labor market, the complexity levels were high in these experiences more than Egypt's standards, with other than that the standards and indictors in Egypt and others of the international experiences were set as per the nature and the specificity of each language, goals and philosophy of each country, with adaptability to the students needs and interests, developments in technology, cultural, social and political changes in their communities.

\section{A Proposed Model of the Standards of Teaching Reading in Egypt}

After reviewing the Standards of Teaching Reading of a group of international experiences and studying the historical development of the Standards of teaching reading in Egypt in certain period of times, a general framework of a suggested model of education standards in Egypt in consistence with the Arabic culture and Egyptian community requirements, characteristics and needs of the Secondary Schools, the following is a presentation of this framework, which handles the Standards of Teaching Reading through three reading cores, as follows:

1. Literary texts, including the following standards: learning the written language symbols and pronouncing it understanding the reading text correctly - writer art and the text structure- text-analysis and response to literature - appreciating and criticizing the reading.

2. Informatics texts, including the following standards: main ideas and details - research skills and study understand and absorption - fast reading while maintaining the understanding.

3. Linguistic texts, including the following standards: analyzing words, fluency and vocabulary development understanding language through the context - understanding the grammatical and morphological structures.

It includes each of the previous standards several indicators achieve the required learning outcomes, according to the specificity of each field, with taking into account the usage of the integrated linguistic, functional and communicative approaches when handling the standards indicators, and equality between the development of what the student reads and the skill used in reading it, interest in the extended, intense, mature and graphic reading, development of innovative, creative, deductive and criticizing thinking, maintaining the values, principles and tendencies, activating the modern technological techniques, facing the crises of extremism, terror, media directed to achieve intellectual security, and the diversity of informatics texts between narration and interpretation and persuasion, guidance and argument, the literary texts include the various literary arts, and gradient in the level of complexity.

\section{References}

Al-Kandari, Abdullah Abdul Rahman, et al., (2010): Teaching Reading, according to American standards of language teaching in Kuwait, Al-Azhar University, College of Education, volume No. 144, Journal No. 7, December / is the argument.

Al-Laboudi, Mona Ibrahim (2011 m): evaluating learning outcomes in reading field in pre-university education in Egypt, Journal of reading and knowledge, volume No. 118, August.

Al-Najjar, Khalid Mohamed Mahmoud (2010): the ability to measure literacy level of students the first three grades of primary school in the light of national standards for teaching reading, magazine reading and knowledge, volume No. 10, April.

Al-Nuseirat, Saleh (2015). Professional Development for Teachers of Arabic Language and Develop their Abilities: a New Shift in Light of standards- based education, Department of Education, Al Hesn University, Abu Dhabi.

Applegate, Mary DeKonty, Turner, Jennifer D. and Applegate, Anthony J. (2010). Will the Real Reader Please Stand up?, The Reading Teacher, Vol. 63, No. 7, April, pp. 606-608

Common Core State Standards Initiative (2010). Common Core State Standards for ENGLISH LANGUAGE ARTS \& Literacy in History/Social Studies, Science, and Technical Subjects, USA. 
Department of Education (2015). Reading The next steps: supporting higher standards in schools, London, March.

Fadlallah, Mohammad Rajab (2016): Towards a school curriculum (developed) of the Arabic language in the public education (curriculum of 2020) proposed project to evaluate the Arabic language curriculum system of public education in Egypt, the Egyptian Association for Curriculum and teaching methods for a radical change in the visions and strategies for the development of educational curriculums, August 3 to 4, vol. 1.

Kalsh, Diab Abdul-Jabbar Diab (2016): The development of the objectives of Teaching Reading for the tenth grade primary of the upper basic stage in Palestine in the light of the international standard levels of Teaching Reading, the Egyptian Society for reading and knowledge, scientific Sixteenth Congress, standards of various education stages and its role in the selection of the educational materials and teaching strategies, in the period of 20-21st July.

Ministry of Education, Egypt (2005). The Document the Arabic Language Curriculum, Egypt.

Ministry of Education, Egypt (2015). The Matrix of Range and Succession for the Criteria and Indicators of the Arabic Language, Egypt.

Ministry of Education, Ontario (2010). Growing Success: assessment, evaluation, and reporting in Ontario schools, (covering Grades 112), First Edition, Queen's Printer for Ontario.

Ministry of Education, UAE: The Developed National Document for the Arabic Language Curriculum from kindergarten to the end of secondary education, United Arab Emirates, Available at: https://www.moe.gov.ae/Arabic/Docs/curriculum

Minnesota Department of Education (2010). Minnesota Academic Standards: English Language Arts K-12, Minnesota.

New Jersey Department of Education (2016). K-12 English Language Arts Revisions, New Jersey Standards Review, January 11.

New Zealand Curriculum Online, available at: https://nzcurriculum.tki.org.nz/content/download/1110/11995/file/Charts1.pdf.

Pennsylvania Department of Education (2014). Academic Standards For English Language Arts Grads 6-12, March, Pennsylvania.

Public Schools of North Carolina (2010). North Carolina Standard Course of Study for English Language Arts, State Board Education, Department of Public instruction, July.

Qatar (2005). The Curriculum Standards for the State of Qatar, available at: www.edu.govqa/Ar/education/pages/grade and subject.aspx

Slavin, Robert E., Cheung, Alan, Groff, Cynthia and Lake, Cynthia (2008). Effective Reading Programs For Middle and High Schools: A Best- Evidence Synthesis, Reading Research Quarterly, International Reading Association. 43(3), July- September, pp. 290 -322.

Soman, Ahmed Ibrahim (2009): Arabic language teaching methods, Amman - Jordan, Dar Zahran.

South Carolina Department of Education (2015). South Carolina College- and Career-Ready Standards for English Language Arts, Columbia, South Carolina.

Tennessee Department of Education (2010). Tennessee's State English Language Arts Standards Grades( 9-10, 11-12), Adopted by the Tennessee state Board of Education, July.

Younis Fathi Ali Ibrahim (2016): Teaching Reading from a modern point of view, the Egyptian Society for reading and knowledge; sixteenth Scientific Conference, reading standards in various stages of education and its role in the choice of teaching materials and teaching strategies, in the period of $20-21^{\text {st }}$ July. 